\title{
Anclaje en el espacio: un estudio sobre anclas recontextualizadas en la franja costera bonaerense
}

\section{(1) Julieta Frère*}

Fecha de defensa: 26 de noviembre de 2018

Directora: Dra. Dolores Elkin

Co-director: Lic. Guillermo Gutiérrez

Jurado: Dres. Carlos Landa y Marcelo Weissel

Las anclas han representado un elemento náutico fundamental a lo largo de la historia. Constituyen un dispositivo de seguridad clave como parte del sistema de amarre y fondeo de una embarcación, además de ser empleadas para la realización de maniobras. Análogamente a la enorme heterogeneidad que han tenido las embarcaciones a través del tiempo, también las anclas han ido transformándose tecnológicamente en términos de forma, tamaño y materiales de fabricación, aunque manteniendo un principio de funcionamiento similar.

A menudo las anclas dejan de funcionar en su contexto primario a bordo de una embarcación debido a diversos motivos, como una falla mecánica, una pérdida incidental o un naufragio. A partir de este punto, frecuentemente algunas anclas son trasladadas hacia un contexto novedoso en el cual cumplen un nuevo rol. Por ejemplo, pueden ser colocadas en el espacio urbano público o privado y ser exhibidas en monolitos, monumentos, instituciones náuticas o establecimientos comerciales. A pesar de que existen numerosos antecedentes en torno al estudio de anclas, son menos usuales aquellos que abordan las que no se hallan en sitios arqueológicos de naufragio, probablemente porque se las considera "descontextualizadas". Aquí las denominamos "recontextualizadas".

Esta tesis se enfoca en el relevamiento y análisis de una muestra de 30 anclas recontextualizadas en la Ciudad de Buenos Aires y los partidos aledaños costeros del Gran Buenos Aires (Tigre, San Fernando, San Isidro, Olivos, Vicente López, Avellaneda y Quilmes). El principal objetivo es explorar el potencial informativo de estas anclas, teniendo en cuenta que a menudo no se conserva ningún dato respecto de su proveniencia o cronología original.

Desde una perspectiva que se enfoca en la vida social de los objetos, trazamos la biografía de las anclas estudiadas teniendo en cuenta los procesos y ciclos en los cuales se ven insertas. Esto permite explorar la relación entre

* Programa de Arqueología Subacuática (PROAS), Instituto de Antropología y Pensamiento Latinoamericano (INAPL). 3 de febrero 1378 (CP C1426BJN) Ciudad Autónoma de Buenos Aires. E-mail: julieta.frere@gmail.com personas y objetos, y cómo en dicha interacción se crea significado (Appadurai, 1986; Flatman, 2003; Gosden y Marshall, 1999; Kopytoff, 1986; Schiffer y Miller, 1999).

Un primer paso es presentar la reconstrucción de su contexto funcional original en el que las anclas son parte del equipamiento de sistema de fondeo y amarre de un navío. Se llevó a cabo la determinación de características tipológicas y morfológicas de las anclas, las cuales nos proveen información sobre las mismas además de indicios respecto del tipo de embarcación en el que pudo haber sido empleada. Para ello, un antecedente útil fue el proyecto de relevamiento de anclas históricas y arqueológicas denominado Big Anchor, de la Nautical Archaeology Society (NAS).

En primer lugar, se llevó a cabo una caracterización general de cada ancla en forma individual. A partir de ello, fue posible determinar a qué tipo de diseño responde, el cual es conocido a partir de la documentación histórica disponible, de investigaciones sobre el tema o por las patentes de sus creadores, las cuales poseen una cronología y región determinada. En segundo lugar, fue posible realizar un cálculo del peso estimado de las anclas, a partir de la correlación entre determinadas relaciones (que varían específicamente de acuerdo al diseño de ancla al que corresponde) plasmadas en tablas que emplean empresas dedicadas a la fabricación de anclas. Por último, una vez calculado el peso de cada ancla, fue posible estimar a partir de fuentes documentales qué tamaño podría haber tenido la embarcación en la cual funcionó.

Asimismo, con el objetivo de analizar la trayectoria histórica a través de la cual las anclas llegaron a sus contextos actuales así como los intereses y construcciones por parte de diversos agentes sociales en torno a las anclas, se integró información histórica disponible (incluida la cartográfica, pictórica y fotográfica) aquella provista por entrevistas semi-estructuradas.

En este sentido, algunas de las conclusiones que se desprenden se relacionan a su cronología, la cual abarca en su mayoría anclas con cepo de metal del siglo XIX y mediados del siglo XX, y en menor medida, anclas del siglo XVIII (probablemente con cepo de madera, actualmente ausente). También se analizaron variables como su distribución espacial, los diseños predominantes, la selección de anclas de acuerdo a su peso, la disponibilidad de información del contexto funcional primario de las anclas y las transformaciones 
morfológicas por las que transitó cada ancla. Asimismo, se dedicó un acápite a analizar los alcances y limitaciones del análisis morfológico en función de los objetivos propuestos, a fines de reconocer nuevas perspectivas para la metodología de trabajo.

Finalmente, se exploraron aspectos de las anclas como objetos con cargas simbólicas específicas, enmarcados en procesos de espacialización. En primer lugar, se hizo hincapié en algunos rasgos en común de las anclas como símbolo de lo marítimo y como demarcadores y enunciadores del paisaje cultural fluvial de Buenos Aires. Por otro lado, se enfatizó que cada ancla posee cargas simbólicas específicas, propias de la construcción de sujetos que circulan en torno a ellas. En este sentido, este trabajo plantea las anclas como objetos polisémicos cuyos significados pueden variar de acuerdo a los sentidos que imprimen las personas a través del tiempo: mientras algunas son consideradas objetos ornamentales, otras son objeto de disputas patrimoniales o territoriales.

\section{Referencias citadas}

"Appadurai, A. (1986). The Social Life of Things: Commodities in Cultural Perspective. New York: Cambridge University Press.

"Flatman, J. (2003). Cultural biographies, cognitive landscapes and dirty old bits of boat: 'theory' in maritime archaeology. International Journal of Nautical Archaeology, 32(2), 143-157.

" Gosden, C. y Marshall, Y. (1999). The Cultural Biography of Objects. World Archaeology, 31(2), 169-178.

» Kopytoff, I. (1986). The Cultural Biography of Things: Commoditization as Process. En A. Appadurai (Ed.), The Social Life of Things: Commodities in Cultural Perspective (pp.64-91). New York: Cambridge University Press.

» Schiffer, M. B. y Miller, A. R. (1999). The Material Life of Human Beings: Artifacts, behavior, and communication. London: Routledge. 